\title{
OPTIMIZATION OF NORMALISING PROCESS PARAMETERS TO ENHANCE MACHINABILITY OF 16MnCr5 STEEL: A STUDY OF MEDIUM SIZED AUTO PARTS INDUSTRY
}

\author{
Guravtar Singh Mann ${ }^{1}$, Lakhwinder Pal Singh ${ }^{2}$ \\ E-Mail Id: guravtar14443@gmail.com
}

${ }^{1}$ Phd, Scholar, Department of Industrial and Production Engineering, Dr. B R Ambedkar NIT Jalandhar, India

${ }^{2}$ Associate Professor, Department of Industrial and Production Engineering, Dr. B R Ambedkar NIT Jalandhar, India

Abstract-Low carbon steel such as $16 \mathrm{MnCr} 5$ is a widely used grade of steel in the manufacturing industry, especially in automobile industry for manufacturing of gears and shafts due to its favourable properties such as toughness, ductility, high tensile strength, good resistance to corrosion. Heat treatment process such as normalizing is often required to be done on raw material to soften the materials and to relieve the stresses. However, if process parameters are not selected properly, the desirable mechanical properties of steel may not be achieved. The present investigation is an attempt to study the effect of the process parameters such as soaking time, temperature and iso-annealing temperature on the hardness of $16 \mathrm{MnCr} 5$ steel using Taguchi method. These were varied and resulting changes in material microstructure were observed. Further, hardness in the range of 160-210BHN and 190-260BHN was observed, with the non uniform distribution of ferrite and pearlite phases. Also, the surface of the samples was found to have coarse grains.

Keywords: Hardness, Taguchi, optimization methods, ANOVA

\section{INTRODUCTION}

Heat treatment is one of the most important processes adapted by various industries, particularly automotive manufacturing industries [1], in order to achieve the desirable properties of components used for various applications. Further, numerous operating conditions are involved in the heat treatment process which make the process complex. Hence, the researchers have focused their attention in optimizing [2], [3] various these operating parameters to achieve high quality components with lower cost. $16 \mathrm{MnCr} 5$ is widely used low carbon steel, with one of its biggest consumer being automotive manufacturing industry to manufacture shafts and gears [4]. Recently, few heat treatment studies were performed on cold and hot rolled $16 \mathrm{MnCr} 5$ samples [5] and found that the surface hardness has increased due to the martensite phase formation. In addition, Laser cladding techniques were used to further enhance the $16 \mathrm{MnCr} 5$ samples [6]. It was reported recently [7] that any anomalies or inefficiencies while carrying out the normalizing process with uncontrolled parameters such as soaking time and iso-annealing temperature can result in a reduced tool life. One such issue was recently observed in a medium sized auto part industry, where there was challenge during the drilling of hole in spider cross with $16 \mathrm{MnCr} 5$ steel. The drill bit was able to cross the case portion but consistently failing in the core area, which caused a significant increase in tooling cost. Hence, the need to investigate on heat treatment parameters to improve tool life is essential.

In present study, heat treatment experiments were performed on the normalized $16 \mathrm{MnCr} 5$ material. The objective of this study is to investigate the impact of annealing process on machinability of $16 \mathrm{MnCr} 5$ material by optimizing the process parameters of soaking time, normalizing furnace temperature, iso-annealing furnace temperature so as to improve the tool life.

\section{EXPERIMENTAL PROCEDURE}

In this section, the experimental setup used for heat treatment of specimens $(16 \mathrm{MnCr} 5$ steel) is described. Industrial induction heater was used for heating the raw material up to $450^{\circ} \mathrm{C}$.

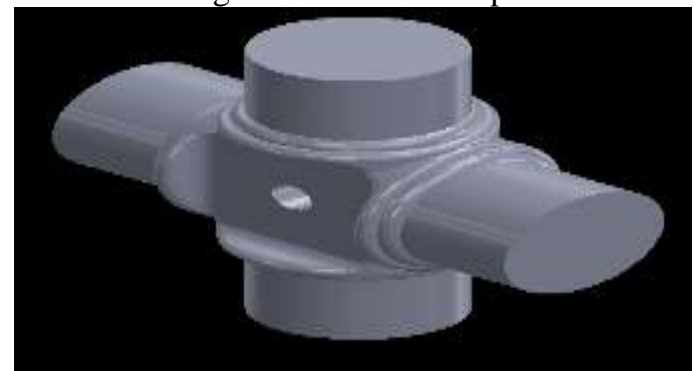

Fig. 2.1 Forged Specimen Made up of 16MnCr5 Steel 


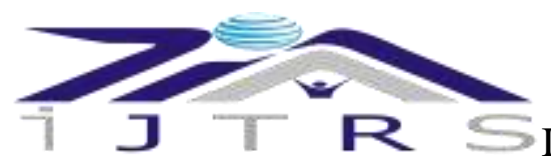

The $16 \mathrm{MnCr} 5$ steel forging process specimen is shown in Fig. 2.1. The normalizing treatment of $16 \mathrm{MnCr} 5$ specimen in sealed quench furnace is carried out in which parameters such as Soaking Time, Normalising Furnace Temperature and Iso-Annealing Furnace Temperature were varied. Later, brinell hardness tests were carried out to observe the changes during the variations in the operating parameters.

Holes were drilled in the component after the normalising process using carbide drills. It was observed that drill tip was not passing smoothly through the core of the work piece due to which there was significant decrease in production rate of components. It was observed, through the brinell hardness tester, that there was variation in the hardness of core and case area as (Fig. 2.2) of the spider component.

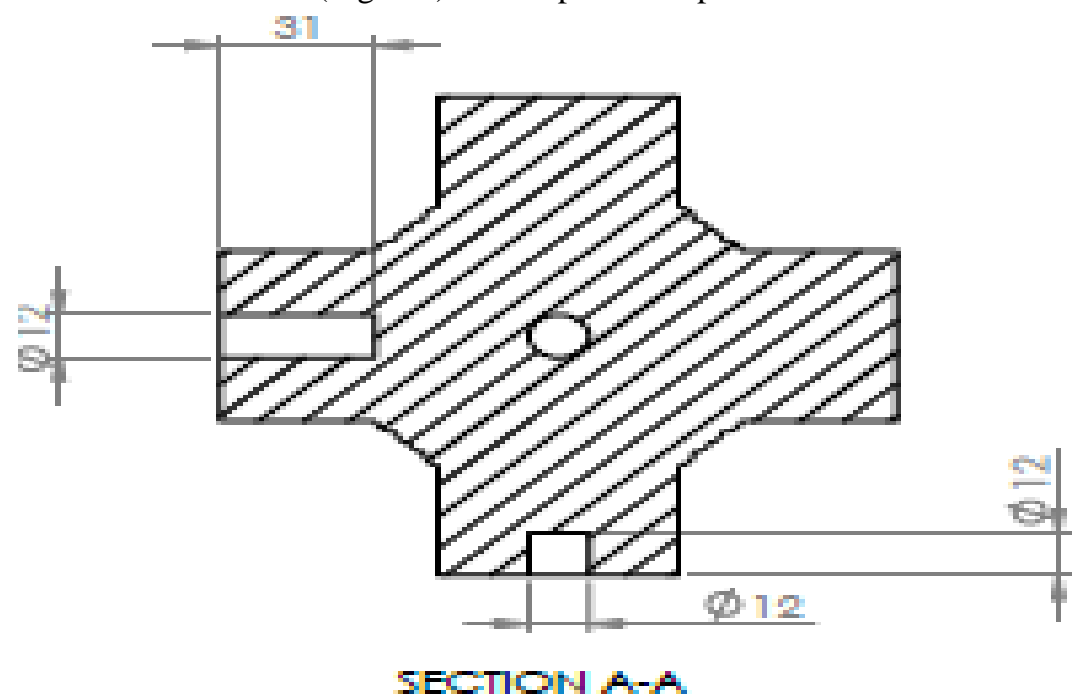

Fig. 2.2 Component Post Drilling Process

The trails were made for setting optimum parameters for normalizing furnace which were affecting the hardness of the Soaking time (20 min, $25 \mathrm{~min}$ and $30 \mathrm{~min})$, Normalizing furnace temperature $\left(910-925^{\circ} \mathrm{C}, 930-936^{\circ} \mathrm{C}\right.$ and $\left.936-955^{\circ} \mathrm{C}\right)$, Iso annealing furnace temperature $\left(620-630^{\circ} \mathrm{C}, 630-640^{\circ} \mathrm{C}\right.$ and Cooling at room temperature in air). It was found that at hardness of $150 \mathrm{BHN}$, there was improvement in drilling process at soaking time $25 \mathrm{~min}$, Normalizing furnace temperature $910-930^{\circ} \mathrm{C}$ and Iso annealing furnace temperature $630-640^{\circ} \mathrm{C}$. Hence, it is now essential to optimize various parameters involved in the heat treatment process so that the high quality product is obtained with lower cost of production. Hence, in the next section, the method of optimizing various parameters is discussed.

\section{OPTIMIZATION OF HEAT TREATMENT PROCESS PARAMETERS USING TAGUCHI METHODOLOGY}

All the industrial experiments involve a significant number of process parameters to be considered. Hence, the complete design requires a large number of experiments to be performed. The process of selecting a significant number of experiments with the relevant information, is called as a partial fraction experiment. Similarly, Taguchi technique provides information on the full set of possibilities for experiments that cover many applications. Moreover, this technique reveals the effect of different parameters on the mean and variance of a process parameters. In addition, the design of experiments by Taguchi technique implements orthogonal arrays while organizing the parameters which affect the process and the recommends the levels at which they must be varied in order to achieve the optimized results. Furthermore, the number of experiments can be put to minimum with fewer resources in lesser time without affecting product quality. Taguchi method is used [8] in the design of the mould for plastic injection and optimization [1]-[3], [9]. While implementing the Taguchi method, the objective function must be established along with the identification of the process parameters and their levels. Later, an appropriate orthogonal array (OA) must be selected and perform experimentation. Finally, analysis on the obtained data must be done and optimal levels must be determined there by confirming the experimentation. The prime objective of the Taguchi technique is to yield high quality product with low cost to the manufacturer. The objective of the present work is to establish the optimal set of the normalising parameters that result in desired hardness of material to achieve maximum production during the drilling process.

Taguchi methodology constitutes control factors and noise factors which affect the process quality. Control factors are generally adjustable according to the needs of the customer. However, noise is the uncontrollable factor, causes variations in the output, contributed due to the experimental environment such as the ambient temperature, humidity, etc. Control factors are the most important in determining the quality of product characteristics. In the present work, the Normalising process of $16 \mathrm{MnCr} 5$ steel is considered with typical control factors (shown in Table-3.1) such as Soaking time (20 $\mathrm{min}, 25 \mathrm{~min}$ and $30 \mathrm{~min}$ ), Normalizing furnace temperature $\left(910-925^{\circ} \mathrm{C}, 930-936^{\circ} \mathrm{C}\right.$ and $\left.936-955^{\circ} \mathrm{C}\right)$, Iso annealing furnace temperature $\left(620-630^{\circ} \mathrm{C}, 630-640^{\circ} \mathrm{C}\right.$ and Cooling at room temperature in air). 
ISSN No.: 2454- 2024 (online)

\begin{tabular}{|c|c|c|c|c|}
\hline \multicolumn{4}{|c|}{ ISSN No.: 2454- 2024 (online) } \\
\hline Category & Parameters & Level 1 & Level 2 & Level 3 \\
\hline $\mathrm{A}$ & Soaking time & 20 min & 25 min & 30 min \\
\hline $\mathrm{B}$ & $\begin{array}{c}\text { Normalizing furnace } \\
\text { temperature }\end{array}$ & $910-925^{\circ} \mathrm{C}$ & $930-936^{\circ} \mathrm{C}$ & $936-955^{\circ} \mathrm{C}$ \\
\hline $\mathrm{C}$ & $\begin{array}{c}\text { Iso annealing furnace } \\
\text { temperature }\end{array}$ & $620-630^{\circ} \mathrm{C}$ & $630-640^{\circ} \mathrm{C}$ & $\begin{array}{c}\text { Cooling at room temp. } \\
\text { in air }\end{array}$ \\
\hline
\end{tabular}

The Taguchi orthogonal array consisting of inner and outer array limits the experiments without compromising on the information on the factors affecting the performance parameters. The inner array is refers to controllable factors with orthogonal array configuration. The outer array indicates the uncontrollable factors contributing to the noise factor. In the present study, it is found that the controllable factors have considerable effect on the quality of the product. Hence, only inner array has been considered for the present investigation with $\mathrm{L}_{9}$ orthogonal array. The experimentation is conducted to understand the influence of three independent variables each at three levels in shown in

Table-3.2.

Table-3.2 The L ${ }_{9}$ Orthogonal Array

\begin{tabular}{|c|c|c|c|c|c|}
\hline \multicolumn{2}{|c|}{ Experiment No. } & P1 & P2 & P3 & S/N \\
\hline 1 & & 1 & 1 & 1 & $\mathrm{~S}_{1}$ \\
\hline 2 & & 1 & 2 & 2 & $\mathrm{~S}_{1} / \mathrm{N}_{2}$ \\
\hline 3 & & 1 & 3 & 3 & $\mathrm{~S}_{3} \mathrm{~N}_{3}$ \\
\hline 4 & & 2 & 1 & 2 & $\mathrm{~S}_{4}$ \\
\hline 5 & & 2 & 2 & 3 & $\mathrm{~S}_{4}$ \\
\hline 6 & & 3 & 1 & 1 & $\mathrm{~S}_{5} / \mathrm{N}_{6}$ \\
\hline 7 & & 3 & 2 & 3 & $\mathrm{~S}_{7}$ \\
\hline 8 & & 3 & 3 & 1 & $\mathrm{~S}_{7}$ \\
\hline 9 & & & & & $\mathrm{~S} / \mathrm{N}_{9}$ \\
\hline
\end{tabular}

$\mathrm{P}$ - process parameter, $\mathrm{S} / \mathrm{N}$ - signal to noise ratio

The Taguchi technique uses the Signal-to-Noise ratio ( $\mathrm{S} / \mathrm{N})$, shown in equation (1) to indicate the new design in comparison with a target characteristics [2]. A high value of $\mathrm{S} / \mathrm{N}$ implies that the desirable properties are much higher than the random effects of the noise factors. The term signal indicates the favourable component of the product characteristics, which is close to its specific characteristics. The term noise indicates the unfavourable component and it represents the deviation in the output characteristics. To evaluate the effectiveness of a design based on the process parameters, $\mathrm{S} / \mathrm{N}$ ratio is used.

$$
\mathrm{S} / \mathrm{N}=-10 * \log \left(\Sigma\left(\mathrm{Y}^{2}\right) / \mathrm{n}\right)
$$

The measured experimental results of hardness of $16 \mathrm{MnCr} 5$ and the corresponding $\mathrm{S} / \mathrm{N}$ ratios of experimental trials are shown in Table-3.3. The average values of $\mathrm{S} / \mathrm{N}$ data for hardness of the specimen were shown in Figure 3. It is clear from Figure 3 that process parameter values at levels $A_{1}, B_{2}$, and $C_{1}$ are the better choices in terms of the hardness.

Table-3.3 Taguchi L9 array for Hardness of 16MnCr5

\begin{tabular}{|c|c|c|c|c|c|}
\hline $\begin{array}{c}\text { Exp. } \\
\text { No. }\end{array}$ & $\begin{array}{c}\text { Soaking } \\
\text { time (A) }\end{array}$ & $\begin{array}{c}\text { Normalizing } \\
\text { Furnace } \\
\text { temperature (B) }\end{array}$ & $\begin{array}{c}\text { Iso annealing } \\
\text { Furnace } \\
\text { temperature }\left({ }^{\mathbf{0}} \mathbf{C}\right)\end{array}$ & $\begin{array}{c}\text { Brinell } \\
\text { hardness } \\
(\mathbf{B H N}) \\
\left(\mathbf{T}_{\mathbf{1}}\right)\end{array}$ & $\begin{array}{c}\text { S/N } \\
\text { Ratio }\end{array}$ \\
\hline 1 & 20 & $910-930^{\circ} \mathrm{C}$ & $620-630^{\circ} \mathrm{C}$ & $165 \mathrm{BHN}$ & $\begin{array}{c}-44.3497 \\
-4141 \\
-44.3497\end{array}$ \\
\hline 2 & 20 & $930-936^{\circ} \mathrm{C}$ & $630-640^{\circ} \mathrm{C}$ & $165 \mathrm{BHN}$ & -45.8007 \\
\hline 3 & 20 & $936-955^{\circ} \mathrm{C}$ & Cooling at room & 195 & -43.5218 \\
\hline 4 & 25 & $910-930^{\circ} \mathrm{C}$ & $630-640^{\circ} \mathrm{C}$ & 150 & -45.8007 \\
\hline 5 & 25 & $930-936^{\circ} \mathrm{C}$ & Cooling at room & 195 & \\
\hline
\end{tabular}


J $\mathrm{R} \subseteq$ International Journal of Technical Research \& Science

\begin{tabular}{|c|c|c|c|c|c|}
\hline 6 & 25 & $936-955^{\circ} \mathrm{C}$ & $620-630^{\circ} \mathrm{C}$ & $165 \mathrm{BHN}$ & -44.3497 \\
\hline 7 & 30 & $910-930^{\circ} \mathrm{C}$ & Cooling at room & 210 & -46.4444 \\
\hline 8 & 30 & $930-936^{\circ} \mathrm{C}$ & $620-630^{\circ} \mathrm{C}$ & 190 & -45.5751 \\
\hline 9 & 30 & $936-955^{\circ} \mathrm{C}$ & $630-640^{\circ} \mathrm{C}$ & 190 & -45.5751 \\
\hline
\end{tabular}

Main Effects Plot for SN ratios

Data Means

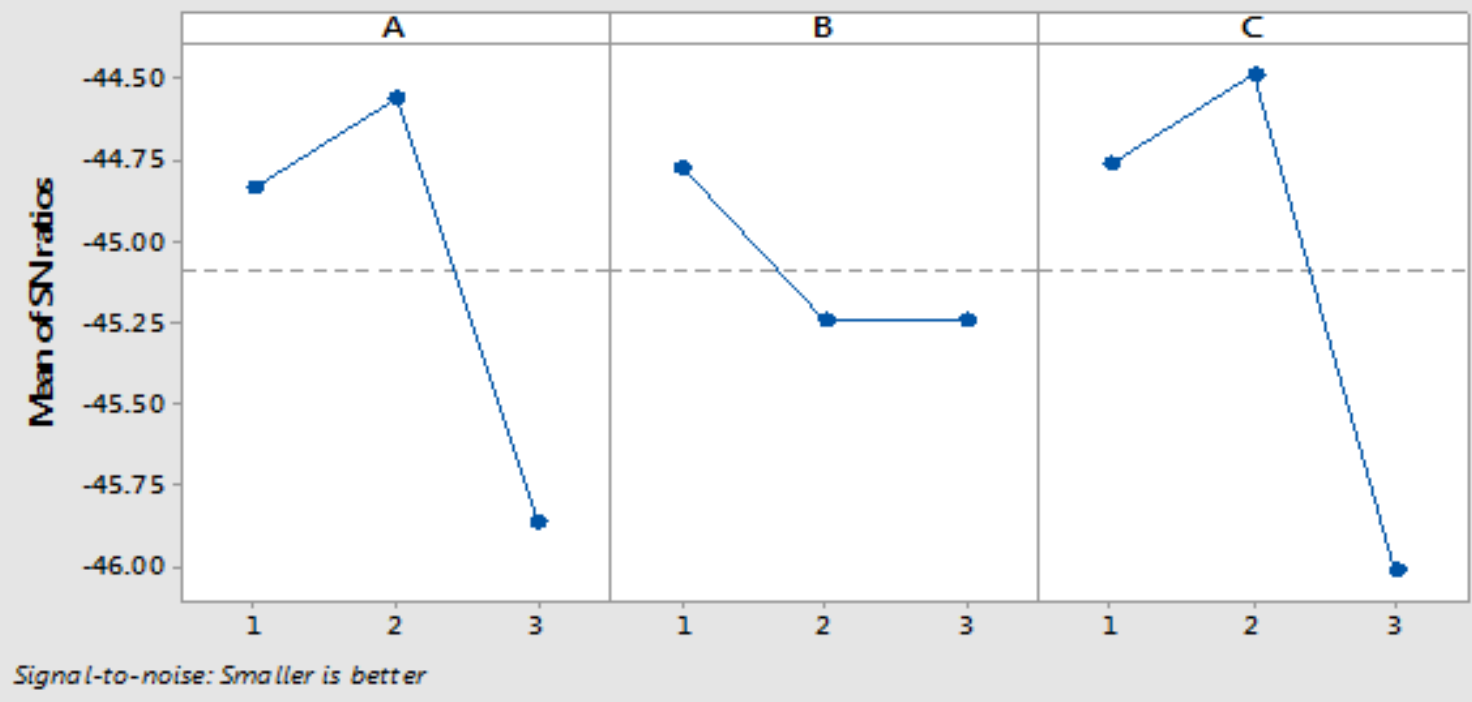

Fig. 3.1 S/N Ratio Plots Indicating Parametric Effect on Hardness

Analysis of Variance (ANOVA) is used to estimate the optimum level of each process parameters in the present work. This ANOVA predicts the relative importance of the process parameters along with estimating the experimental errors. It gives the percentage of contribution of each process parameter and provides information on the effect of different factors on experimental results. The ANOVA of raw data (

Table-3.4) shows that all the selected process parameters are affecting the hardness of specimen considerably.

Table-3.4 ANOVA Results for Hardness of 16MnCr5

\begin{tabular}{|c|c|c|c|c|}
\hline $\begin{array}{c}\text { Source of } \\
\text { variation }\end{array}$ & $\begin{array}{c}\text { Degree of } \\
\text { Freedom }\end{array}$ & Sum of square & Mean square & F-test \\
\hline Treatment & $\mathrm{p}-1$ & 568526 & $\begin{array}{c}\text { MSTR=71065.63 } \\
\text { MSE }=1726\end{array}$ & 41.7 \\
\hline Error & $\mathrm{p}(\mathrm{r}-1)$ & 15526 & & \\
\hline Total & $\mathrm{rp}-1$ & 584051 & & \\
\hline
\end{tabular}

Three confirmation experiments were conducted at the optimum levels of the process parameters. The mean value of tensile strength at the optimal setting of the process parameters was found within the confidence (95\%) interval of the predicted optima of quality characteristics.

\section{DISCUSSION}

It can be observed from results that all the three parameters have strong influence on the hardness component. Also, among all parameters the required hardness is obtained at soaking time $25 \mathrm{~min}$, Normalizing furnace temperature $910-930^{\circ} \mathrm{C}$ and Iso annealing furnace temperature $630-640^{\circ} \mathrm{C}$. (Fig 2.1 showing failed specimen before heat treatment process). As thickness of low carbon steel can have a significant effect on the cooling rate and thus the resulting microstructure. Therefore there are chances that cooling rate might have varied which affected the hardness of the material due to which non uniform microstructure have formed which effected the smooth drilling of the components as soaking is found as the most prevalent factor as it plays important role in microstructure transformations of any material. The requirement of the customer is met with setting the parameters in such a way that the Soaking time must be 30 Min with Normalizing temperature of range 935$945^{\circ} \mathrm{C}$ and Iso annealing furnace temperature of $640-650^{\circ} \mathrm{C}$. Hence this set of combination was proposed to 


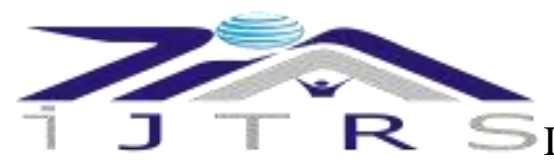

automotive industry as normalizing process plays major role hardness of components which is again related to tool life. S/N ratio plot displaying the parametric response indicating the line diagrams is shown in Figure 3 . It has been found that with higher levels of soaking time, iso annealing temperature and normalizing time have contributed towards the higher hardness. In Fig for parameter A (soaking time) required hardness is at level 2 which is less than level 1 and level 3. For parameter B (normalizing furnace temperature) the hardness increases from level 1 to 3 while for Parameter C (Iso annealing furnace temperature the hardness increases from level 1 to 2 and is maximum at level 3 . It can be observed from microstructure that with $44 \%$ ferrite and $49 \%$ pearlite as (shown in Fig. 4.1) drilling of the component becomes smooth hence good production of components.

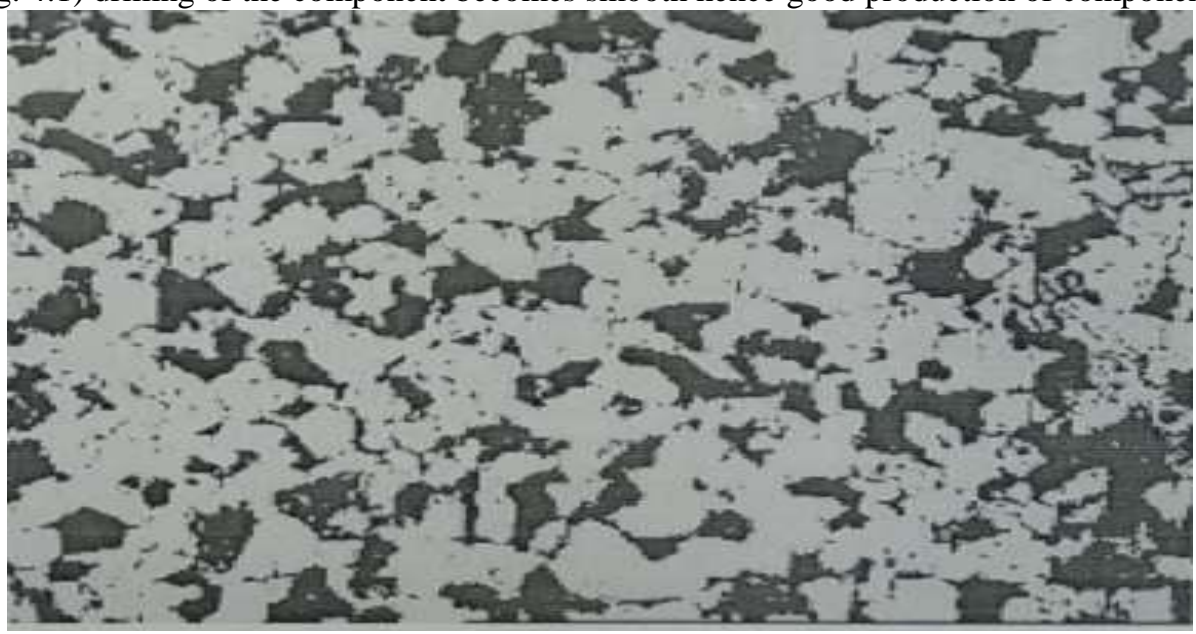

\section{CONCLUSIONS}

Fig. 4.1 Microstructure Post Normalizing Process

The hardness of $16 \mathrm{MnCr} 5$ steel for manufacturing of automotive component Pre and post heat treatment has been investigated using the Taguchi method. Three important process parameters i.e. soaking time, normalizing furnace temperature and Iso annealing furnace temperature in normalizing process and their effect on machinability have been studied. The following conclusions can be drawn from the present investigation:

The optimum levels of the soaking time, normalizing furnace temperature and Iso annealing furnace temperature have been established for getting minimum hardness for machining of spider cross (16Mncr5 steel).

Maximum no of pieces were drilled, when the parameters for the process were set with 25 min soaking time, normalizing furnace temperature of $910-930^{\circ} \mathrm{C}$ and iso annealing furnace temperature at $630-640^{\circ} \mathrm{C}$ respectively as desired value of hardness i.e. 150-190 BHN was also achieved. It is also concluded that variation in time parameters was found influencing normalization process more than other parameters. Confirmation tests were carried out to verify the predicted optimal conditions. Values of estimation gain and confirmation gain were found close each other.

\section{REFERENCES}

[1] A. Khajanchee, S. K. Pradhan, and P. Jain, "Experimental Investigations To Optimize Process Parameters For CO2 Laser Welded Alloy Steel Automotive Gears," Mater. Today Proc., vol. 5, no. 5, Part 2, pp. 11636-11654, 2018.

[2] A. Khajanchee and S. K. Pradhan, "Comparison and Identification of Suitable Multi-Response Optimization Technique for Laser Welding Process Parameters,” Mater. Today Proc., vol. 5, no. 5, Part 2, pp. 12197-12208, 2018.

[3] A. Khajanchee and S. K. Pradhan, "Optimization Of Process Mean Setting For CO2Laser Welding Process For Alloy Steel Automotive Gears With Application Of Taguchi Loss Function And Fraction Defective Method,” Mater. Today Proc., vol. 5, no. 5, Part 2, pp. 11977-11989, 2018.

[4] K. Funatani, "Heat Treatment of Automotive Components : Current Status and Future," Production, vol. 57, no. 4, pp. 381-396, 2004.

[5] İ. Yeğen and M. Usta, "The effect of salt bath cementation on mechanical behavior of hot-rolled and colddrawn SAE 8620 and 16MnCr5 steels," Vacuum, vol. 85, no. 3, pp. 390-396, 2010.

[6] J. H. Ouyang, S. Nowotny, A. Richter, and E. Beyer, "Characterization of laser clad yttria partiallystabilized ZrO2 ceramic layers on steel 16MnCr5," Surf. Coatings Technol., vol. 137, no. 1, pp. 12-20, 2001.

[7] A. Kohli and H. Singh, "Optimization of processing parameters in induction hardening using response surface methodology," Sadhana - Acad. Proc. Eng. Sci., vol. 36, no. 2, pp. 141-152, 2011.

[8] S. H. Tang, Y. J. Tan, S. M. Sapuan, S. Sulaiman, N. Ismail, and R. Samin, "The use of Taguchi method in the design of plastic injection mould for reducing warpage,” J. Mater. Process. Technol., vol. 182, no. 1, pp. 418-426, 2007. 
7 J $\mathrm{R}$ \& International Journal of Technical Research \& Science

[9] J. A. Ghani, I. A. Choudhury, and H. H. Hassan, "Application of Taguchi method in the optimization of end milling parameters,” J. Mater. Process. Technol., vol. 145, no. 1, pp. 84-92, 2004. 